\title{
Desmontando el mito
}

Reseña: Si muere Duchamp, de Paula Arrieta Gutiérrez. Santiago, Chile: Tiempo Robado, 2021

1

Rodrigo Canales

UNIVERSITAT POLITÈCNICA DE VALÈNCIA

A veces la memoria es un cuchillo Siri Hustvedt, Recuerdos del futuro

La reciente publicación de Si muere Duchamp, viene a sumar una voz interesante en un contexto más amplio, por lo que intentaremos enfocar la obra de Paula Arrieta Gutiérrez como un eslabón de una cadena que no empieza ni termina con las páginas de su obra.

Si muere Duchamp habla de los problemas del arte, pero también habla de los problemas de la sociedad patriarcal en una perspectiva feminista de avanzada, en el entendido que se exponen tramas que englobaremos bajo la etiqueta de "lo invisible", que presentan mayor dificultad a la hora de ser percibidas por el conjunto social como problema efectivo, lo que lleva a una compleja y lenta asimilación e integración en el pacto social. Es en en esa zona desde donde articula su discurso.

Ante todo, indicaremos algunas nociones esenciales sobre esta publicación. Se trata de un libro breve, de aquellos que se pueden leer en una tarde y un par de cafés. En este caso, la síntesis aparece como un mérito pues en el desarrollo se incrustan temas importantes, se refieren autores y obras, y se ingresa a mundos personales de la autora que nos propone una narración en primera persona, desafiando las rígidas convenciones de la academia. El libro de Arrieta Gutiérrez se impone como un aporte en la comprensión teórica del oficio del artista, de sus referencias y del lugar que ocupa un creador en nuestra sociedad, desde una perspectiva de género que refuerza la propuesta.

Estos propósitos, en sí mismos, no son presentados como una novedad investigativa, pues son muchos los autores que pretenden definir los límites de la actividad creadora. Sin embargo, aquí es donde Arrieta nos propone, a mi juicio, un primer acierto: no intenta generar un mapa de la actividad mundial o local, repasando grandes creadores, desmenuzando las condiciones expositivas y de mediación, denunciando la intervención del mercado en las operaciones vinculadas a las obras de arte o su correspondiente fetichización; lo que nos ofrece Si muere Duchamp es mucho más sencillo pero inquietante: nos enfrenta a la posibilidad del desmontaje

\footnotetext{
${ }^{1}$ Doctorando en Artes: investigación y producción en la Universitat Politècnica de València, adscrito al Centro de Investigación Arte y Entorno (CIAE) de la Facultad de Bellas Artes. ${ }^{\circ}$ ORCID: 0000-0001-8375-2715
} 
del mito fundacional del arte contemporáneo, anclado de modo sutil pero eficiente a un discurso de esencia patriarcal. Es en este ángulo donde se abren los mundos de la propuesta.

Si muere Duchamp se estructura como un ensayo, precedido de un interesante prólogo, La fe ciega, a cargo de Alia Trabucco Zerán y seguido de un conjunto de Anotaciones medianamente organizadas, que desnudan o dejan entrever parte del proceso de creación. La parte central y más extensa, despliega lo medular de la publicación. En poco más de ochenta páginas estructura una trenza narrativa, con un estilo que se aleja de la conceptualidad académica, para conducirnos por pequeños y privados detonadores que activan la reflexión.

Esta trenza escritural se sostiene en tres elementos nítidos: una indagación sobre las versiones que ponen en duda la autoría de La fuente (1917), el famoso ready made de Duchamp, que sería idea y obra de la singular artista y performer de vanguardia, la baronesa Elsa von FreytagLoreinghoven. En segundo término, vincula otros momentos de la historia del arte al relato, donde también se incrustan operaciones de corte patriarcal, destacando la muerte de Ana Mendieta (1985). La tercera avenida narrativa se construye con trazos de experiencias personales de la autora, recuerdos y reflexiones que se superponen en la escritura y que tienden puentes para hacer circular ideas. La escritura es, por tanto, un ejercicio personal, del mismo modo que lo es el acto creativo que nace de pulsiones determinadas. Es en esta fase personal de la escritura donde emergen tres conceptos centrales de la operación narrativa: exclusión, invisibilización, poder.

Si muere Duchamp usa como resorte provocador la posibilidad de que hayamos construido la historia del arte contemporáneo sobre un mito que, como tal, narra una fantasía perfecta. Pero este asunto no queda resuelto en estas páginas, porque este libro no tiene la vocación de resolver ninguna pregunta, sino de plantearlas y desplegarlas de modo que empiecen a ocupar un espacio relevante. Con esto, Arrieta hace palpable nuestra necesidad (ver ansiedad) aprendida de resolver, definir y configurar el mundo en una lógica positivista, que no es otra cosa que una perspectiva patriarcal. Si muere Duchamp nos saca de la caja y señala que - en especial como artistas-, no es necesario resolver, sino que estar disponible a escuchar y ser escuchado porque "no cualquiera puede hablar y ser escuchado (...), el arte no es solo un ejercicio público, sino también de poder" (94).

En este sentido, la reflexión se incrusta en uno de los problemas de la modernidad, como lo son las "acciones depuradoras" del sistema (Horkheimer y Adorno 168), donde también se encuentran las represiones propias de una estructura patriarcal que invalida sistemáticamente la existencia femenina fuera del canon, principalmente en los campos tradicionales de la masculinidad. El ejercicio estilístico, donde el protagonismo es de subjetividad del hablante, es un riesgo consciente que adopta la autora, sabiendo - suponemos- que no resulta válido restituir la figura femenina con los códigos establecidos.

El libro tiende a clausurar su sistema conceptual en esta operación, adquiriendo sentido orgánico en sí mismo, justificando sus herramientas bajo las mismas condiciones estructurales que propone. Y eso no es poco, es una propuesta de resistencia que en efecto transforma nuestra lectura en un aprendizaje de los modos de conocer, y no únicamente de los objetos a comprender, en una línea que se inscribe dentro de la lógica decolonial, tal como indica Guasch al afirmar que "si el colonialismo significaba colonizar la mente, entonces la resistencia a ello significaba "descolonizar mentes"” (65).

Decía al principio, que este libro se inscribe como un eslabón en una cadena de esfuerzos, los que va reconociendo y develando de manera acertada, incluso con cierta progresión 
dramática. Nos enteramos de una pequeña (aunque significativa) anécdota donde Arrieta narra su paso, a principios de este siglo, por la Escuela de Ingeniería y Ciencias de la Universidad de Chile, cuando se vio sometida al rito de iniciación de "elección de reina", y frente a la abrumadora mayoría masculina "cada una de las mujeres del curso tenía que subir a la mesa" (77) del profesor para ser evaluada por la horda. Antes, ya nos hemos conectado con algunos detalles del caso de Martín Pradenas, violador y nombre ícono de la violencia sexual contra mujeres en Chile, de quien su defensa declaró en el juicio que "tiene aspecto de actor de cine" (56), con lo que se pretendía desvirtuar las acusaciones. Y se suma en este mosaico, el caso de Ana Medieta, notable artista disminuida en la sombra de su pareja, el también artista Carl Andre, y cuya muerte fue rotulada como suicidio, desacreditando todos los indicios de violencia doméstica. Estos relatos, que asoman movidos por hilos en apariencia emocionales, se enmarcan dentro de la historia de Duchamp y las dudas sobre la autoría del La fuente en desmedro de la baronesa, relato oficial que se suma a esa dinámica en "que los hechos sorprendentes aparezcan de la nada, como una revelación, lo cual habitualmente es una mentira que sin embargo cuenta con muy buena prensa" (28).

Paula Arrieta Gutiérrez maneja la narración de modo hábil, aportando otros pequeños elementos biográficos que nos entregan luces de su posición frente al arte y la sociedad. Al mismo tiempo, suma conceptos precisos sobre los eventos relatados, como el neologismo de la brasileña Suely Rolnik, cuando agrupa las operaciones descritas bajo el cartel de antrofaloegologocéntrica, palabra donde "se concentrarían las directrices que rigen el pensamiento (antropocéntrico, falocéntrico, egocéntrico, logocéntrico) por medio de la repetición de fórmulas de solución desde una cartografía ya conocida y que impide, por tanto, la irrupción de la creatividad, de formas nuevas de construir la realidad" (59)

En esta definición se encierra una de las claves para aproximarse a este libro. Es en sí mismo un intento por dar espacio a la creatividad y a "nuevas formas de construir realidad". Sería un error considerar esta creatividad como, por ejemplo, el ejercicio del flâneur, figura masculina, principalmente - que se levanta como referencia de artista que observa mientras deambula por la sociedad. Se refiere a una creatividad definida por objetivos sociales y políticos, que busca desmantelar las estructuras canónicas porque son justamente esos mecanismos los que se encuentran acusados. Por cierto en estas páginas sí existe observación respecto del entorno, muy aguda y muy distinta a la del estereotipo, la que se refrenda en la elección de elementos que componen el relato y, por sobre todo, en la honestidad despojada que fluye entre las líneas de $S i$ muere Duchamp. Arrieta nos recuerda que "mientras un artista hombre piensa, proyecta, diseña, construye, una artista mujer sólo puede sentir, actuar bajo impulsos incontrolables, confundir obra y realidad" (66) y este libro nos invita a descubrir las posibilidades que hemos despreciado al negarnos a sentir, a dejarnos llevar por los impulsos y a confundir la obra con la realidad, como si esto último fuera una sola cosa inmutable y monolítica.

Da la impresión, decía en un inicio, que el trabajo de Arrieta Gutiérrez se configura como un eslabón dentro de una serie de aportes que, por dar alguna fisonomía temporal, van desde el atrevimiento de la guillotinada Olympe de Gouges con su declaración universal de los derechos de la mujer y la ciudadana de (1791), la valentía de Josephine Butler, la genialidad de Simone de Beauvoir, Gabriela Mistral, Hannah Arendt, Rebecca Solnit, Pía Barros, Silvia Rivera Cusicanqui, Rita Ferrer, Nelly Richard, Diamela Eltit, Siri Hustvedt, Gloria Anzaldúa, Paz Errázuriz y muchas, muchas, otras mujeres - pensadoras, activistas y creadoras- que con 
audacia construyen espacio en mundos masculinizados (o tal vez crean mundos en espacios masculinos), donde deben demostrar cada vez la importancia de su aporte. Ellas han sido inspiración.

Al leer las páginas de Arrieta también pienso en la selección femenina de fútbol, en la presidenta del colegio médico, en la expresidenta de Chile, en la presidenta de la federación de ajedrez, en la machi candidata electa constituyente, y también pienso en mi abuela que, huérfana de niña, se hizo profesora, dirigió una escuela, crió tres hijos y con algo más de suerte - de esa negada por cuestiones de género- hubiera optado a un cupo para ser concertista en piano.

Derribar los mitos fundacionales, como ejercicio consciente, nos proporciona la oportunidad de reescribir las historias, las colectivas y las personales, hecho transformador de la realidad. Lo real, territorio en disputa permanente, es el producto de una suma de experiencias contrastado con un cúmulo de expectativas, las que llamaremos posibilidades. El cómo entendamos nuestras experiencias, el lugar que nos construye antes de ser lo que somos, definirá las posibilidades que seamos capaces de ver. Solnit afirma que "si el cuerpo es la experiencia de lo real, leer con los propios pies es real de un modo en que leer con los ojos no lo es" (113). No estoy en posición de dar por cierto lo que se afirma, pero el arrojo de atreverse a leer la realidad desde otro lugar, sin duda nos entregará una nueva experiencia y generará nuevas posibilidades.

Esa es la invitación que nos hace Si muere Duchamp, a redibujar el estado de las cosas, a poner en duda el paradigma, a hacer efectivo el condicional, aquel "si" que se incrusta en el título. Es una arenga a descolonizarnos de la idea del urinario vanguardista, desmontando su significado para el arte y los artistas. Y eso no es poco.

\section{Referencias}

Arrieta Gutiérrez, Paula. Si muere Duchamp. Santiago, Chile: Tiempo Robado, 2021. Impreso.

Guasch, Anna Maria. El arte en la era de lo global 1989-2015. Barcelona, España: Alianza Editorial, 2016. Impreso.

Horkheimer, Max, y Theodor Adorno. Dialéctica de la ilustración. Madrid, España: Trotta. 1998. Impreso.

Solnit, Rebecca. Wanderlust: una historia del caminar. Madrid, España: Capitán Swing. 2015. Impreso. 